\title{
Low expression of brown and beige fat genes in subcutaneous tissues in obese patients
}

\author{
Aishah Al-Amrani ${ }^{1,2}$, Mouaadh AbdelKarim ${ }^{3}$, Mohammad AlZabin ${ }^{4}$, Mohammad Alzoghaibi $^{5}$
}

\author{
${ }^{1}$ PhD student, Department of Physiology, Faculty of Medicine King Saud University, \\ Riyadh, Saudi Arabia \\ ${ }^{2}$ Faculty of Applied Medical Sciences, Tabuk University, Tabuk, Saudi Arabia \\ ${ }^{3}$ Department of Physiopathology of Inflammatory Bone Diseases, University \\ of the Littoral, Boulogne sur Mer, France \\ ${ }^{4}$ Department of Surgery, Kingdom Hospital, Riyadh, Saudi Arabia \\ ${ }^{5}$ Department of Physiology, Faculty of Medicine, King Saud University, Riyadh, \\ Saudi Arabia
}

Submitted: 16 February 2018

Accepted: 20 May 2018

Arch Med Sci 2019; 15 (5): 1113-1122

DOI: https://doi.org/10.5114/aoms.2018.76684

Copyright $\odot 2018$ Termedia \& Banach

\section{Abstract}

Introduction: The molecular mechanisms behind obesity pathogenesis remain largely undefined. Impairment in the browning process of subcutaneous tissues proposed to contribute to obesity pathogenesis. In the current study, we aimed to assess whether the expression of brown fat genes in subcutaneous tissues in obese patients is altered as compared to non-obese patients.

Material and methods: Participants were recruited from patients undergoing general surgeries. At the same site of surgery, biopsies were taken from the abdominal subcutaneous tissues from each participant, along with a venous blood sample. The expression of BAT genes was measured using a real-time PCR method. Serum FGF21 was measured using an ELISA kit, and the serum blood lipid profile was measured using the Dimension VistaTM 1500 System.

Results: A total of 58 surgical patients was involved. A low expression of BAT genes was observed in the groups with higher body mass index (BMI) $\left(<30 \mathrm{~kg} / \mathrm{m}^{2}\right)$ as compared to the groups with lower BMI $\left(>30 \mathrm{~kg} / \mathrm{m}^{2}\right)$. The expression of CIDEA and CITED1 was significantly higher in the patients with normal weight as compared to obese $(p=0.01$ and $p=0.02$, respectively). A significant negative correlation was found between the expression of BAT genes and BMI in patients with $\mathrm{BMI}<35 \mathrm{~kg} / \mathrm{m}^{2}$. However, the strongest negative correlation was observed in the expression of CIDEA $(r=-0.5$, $p=0.004)$, followed by TBX1 $(r=-0.4, p=0.01)$, CITED1, and ZIC1 $(r=-0.4$, $p=0.03)$. Whereas the correlation of UCP1 with $\mathrm{BMI}$ remained insignificant $(r=-0.29, p=0.08)$. When including patients with BMI $>35 \mathrm{~kg} / \mathrm{m}^{2}$, the correlation decreased and became insignificant $(p=0.08)$. No significant correlation was found between the expression of BAT genes and blood lipid profiles $(p>0.05)$. Serum FGF21 was positively and significantly correlated to the expression of UCP1 $(r=0.56, p=0.02)$ and TBX1 $(r=0.62, p=0.01)$, however, this correlation was missing in patients with severe obesity. Conclusions: Our data suggested that brown and beige genes expression in abdominal subcutaneous tissues is dysregulated in patients with obesity. Further studies are needed to investigate the role of browning of subcutaneous tissues in regulating body weight and metabolism in human.

Key words: uncoupling protein 1, CIDEA, CITED1, TBX1, ZIC1.

\author{
Corresponding author: \\ Aisha Al-Amrani \\ Physiology Department \\ King Saud University \\ Al-Nakheel Area \\ P.O. BOX 420068 \\ Riyadh 11322 \\ Saudi Arabia \\ Phone: +966506490785 \\ E-mail: aiashah_Atiah@ \\ hotmail.com
}




\section{Introduction}

Brown adipose tissue (BAT) is a type of fat tissue distinctive from white adipose tissue (WAT) in its ability to disperse energy through nonshivering thermogenesis, a process mediated by the presence of uncoupling protein 1 (UCP1) in the inner mitochondrial membrane, which is abundant in BAT [1]. Human active BAT has been found to be located in the extrascapular, cervical, mediastinal, and retroperitoneal regions in adults and in the extrascapular region in infants [2]. Accumulated evidence indicates that BAT activities resist obesity and its metabolic dysregulation. Interestingly, BATlike cells can be induced throughout WAT through a process called "browning," which expresses high levels of UCP1 [3]. These inducible BAT-like tissues are called "brite" or "beige" adipose tissues (bAT). Using a range of stimuli, bAT was found to act with high expression of UCP1 and a higher respiration rate [3]. Human bAT is present mainly in the subcutaneous WAT depots [4]. It has been demonstrated in rodents that browning of WAT (bAT) resists obesity and its metabolic complications [5]; however, this has not been verified in humans.

Assessment of BAT activities in the classic BAT areas in obese individuals by radiological images revealed that there is impairment and a decrease in the thermogenesis process in those individuals compared with non-obese individuals $[6,7]$. However, whether there is also impairment in the browning process of WAT during obesity is unknown in humans.

Fibroblast growth factor type 21 (FGF21) is an endocrine hormone produced mainly by the liver through regulation of energy hemostasis and controlled adiposity [8]. Administering FGF21 to animal models reduces obesity and insulin resistance [9]. FGF21 has been found to be a powerful inducer of BAT activities and browning of WAT [10-12]. The association of serum FGF21 with bAT has not been confirmed in humans.

In the current study, we assessed whether the expression of BAT/bAT genes in subcutaneous tissues in obese patients is reduced compared with non-obese patients and to assess whether the expression of BAT/bAT genes is correlated with body mass index (BMI), blood lipids and FGF21.

\section{Material and methods}

\section{Recruitment of participants}

The study included 58 patients undergoing general surgery. Ethical approval of the study protocols was obtained from the Institutional Review Board (IRB) of the College of Medicine, King Saud University (Ref. No. 16/0283/IRB). Ethical and administrative approvals were also received from the research unit at Kingdom Hospital. Informed consent, approved by the IRB, was obtained from each participant after we explained the method, purpose of the study, and the potential risks associated with participation. Patients with acute or chronic current disease conditions, such as renal or cardiac disease or cancers, were excluded from the study. The demographic data (age, sex, etc.) were obtained from patient files. The confidentiality and anonymity of the participants' obtained data were maintained during the study, including data obtained from all the study analytical protocols. Weight and height were measured using the available medical scales at Kingdom Hospital. The BMI was calculated from the weight and height, as previously described [13].

\section{Sample collection and preservation}

About $3 \mathrm{ml}$ of venous blood was drawn by an expert phlebotomist into a gel separator tube from each participant. The tubes were then centrifuged at $4^{\circ} \mathrm{C}$ for $15 \mathrm{~min}$ at $1500 \mathrm{~g}$ within $30 \mathrm{~min}$ to obtain serum. The obtained serum was allocated and frozen at $-80^{\circ} \mathrm{C}$ until biochemical analysis. A biopsy (1 gm) was obtained by the surgeon from subcutaneous fat tissue in the abdominal area at the same site of surgical incision. After extraction, the biopsies were impeded directly in an RNA stabilization solution (MCLAB, South San Francisco, (A, USA) and frozen at $-80^{\circ} \mathrm{C}$ until analysis.

\section{RNA extraction}

A combination of guanidinium thiocyanatephenol-chloroform extraction and column-based methods was used. In brief, around $1 \mathrm{ml}$ of TRIGent (CAT. No. K5161, Biomatik, Wilmington, DE, USA) was added to $50-100 \mathrm{mg}$ of tissue in a small micro tube. Then, the samples were homogenized using a power homogenizer. After $10 \mathrm{~min}$ of incubation at room temperature with intermittent vortexing, $200 \mu \mathrm{l}$ of chloroform (Sigma-Aldrich, St. Louis, MO, USA) was added to each tube. The tubes were then vortexed for $30 \mathrm{~s}$ and incubated at room temperature for $5 \mathrm{~min}$. This was followed by centrifugation for $10-15 \mathrm{~min}$ at $12,000 \mathrm{~g}$ for phase separation, after which the upper aqueous layer was transferred to a new tube. About $500 \mu \mathrm{l}$ of isopropanol was added to the aqueous phase. After incubation at room temperature for $10 \mathrm{~min}$, the tube was transferred to a spin column (Jena Bioscience, Jena, Germany) and then centrifuged for $1 \mathrm{~min}$ at $8000 \mathrm{~g}$ to precipitate RNA. The precipitated RNA in the column was washed twice by adding $0.5 \mathrm{ml}$ of $70 \%$ ethanol before additional centrifugation at 11,000 for 2 min. The RNA was eluted by adding 30 to $50 \mu \mathrm{l}$ of PCR grade water to the column and then incubated at room temperature for 2 min. Following this, the precipitated RNA was centrifuged again at 10,000 for 2 min. The RNA quality and quantity were measured using NanoDrop ND-1000 UV-VIS Spectrophotom- 
eter version 3.2.1. The RNA quality was $>1.8$ of the $A 260 / 280$ ratio. Then, the RNA was stored at $-80^{\circ} \mathrm{C}$ until used.

\section{Reverse transcription and real-time PCR}

The RNA was transcribed to cDNA using the Script cDNA synthesis kit (Cat. No. PCR-511L, Jena Bioscience) according to the manufacturer's instructions. In brief, around 1000 ng of RNA was added to the cDNA synthesis reaction mix before incubation using the thermal cycler at $50^{\circ} \mathrm{C}$ for $60 \mathrm{~min}$. The resulting cDNA was stored at $-20^{\circ} \mathrm{C}$. The cDNA was used in a real-time PCR reaction using a real-time green master mix (SYPER Green equivalent) with a lowROX kit (Cat. No. PCR-316L, Jena Bioscience), according to the manufacturer's instructions. To give a brief summary of the process, about $1000 \mathrm{ng}$ of cDNA and the primer set were added to the PCR reaction mix. After brief centrifugation, the reaction was run using the qTOWER $^{3}$ real-time PCR system (Analytik Jena, Jena, Germany) available at Stem Cells Research Center at College of Medicine at King Saud University. The thermal conditions were $10 \mathrm{~min}$ at $94^{\circ} \mathrm{C}$ for initial denaturation and polymerase activation, followed by 40 cycles of $20 \mathrm{~s}$ denaturing $\left(94^{\circ} \mathrm{C}\right)$ and $60 \mathrm{~s}$ annealing/elongation $\left(62^{\circ} \mathrm{C}\right)$. The primer sequences are listed in Table I. All reactions were run in triplicate. The $\beta$-actin mRNA expression level was used to normalize the mRNA expression of the other genes. The comparative Ct $\left(2^{-\Delta \Delta C t}\right)$ method was used to calculate the fold change in the expression of the genes of interest.

\section{Biochemical analysis}

Serum FGF21 was assessed using the human serum FGF21 ELISA kit (Catalog No. EF3021-1, Assaypro, St. Charles, MO, USA), according to the manufacturer's instructions. Blood lipid profile was measured in the obtained sera using the Dimension Vista 1500 System (Siemens Healthcare, Malvern, PA, USA) available at King Khaled University Hospital (KKUH) laboratory department at King Saud University.

\section{Statistical analysis}

The GraphPad Prism 7.04 software (GraphPad, San Diego, CA, USA) was used in all the data analyses. The data were presented as mean and standard deviation if normally distributed and as median and range if abnormally distributed (Anderson-Darling normality test). The differences between the groups were assessed using the Kruskal-Wallis (nonparametric) test followed by Dunn's multiple comparison test if not normally distributed and by an ANOVA test if normally distributed. A Spearman correlation test (nonpara- metric) was used to assess whether there was a correlation between the study variables. The result was considered significant if $p<0.05$.

\section{Results}

\section{Characteristics of study participants}

The characteristics of the participants of this study are presented in Table II. A total of 58 surgical patients were involved. Twenty-three were undergoing laparoscopic sleeve gastrectomy, 16 were undergoing abdominal hernia repair, and 19 were undergoing laparoscopic cholecystectomy. The mean age was $32 \pm 7.5$ years, and the mean BMI was $33.7 \pm 8 \mathrm{~kg} / \mathrm{m}^{2}$. The male percentage was $25 \%$. To facilitate comparisons, participants were grouped according to their $\mathrm{BMI}$ into 4 groups: a normal weight group (BMI $18-25 \mathrm{~kg} / \mathrm{m}^{2}$ ), an overweight group (BMI $25-30 \mathrm{~kg} / \mathrm{m}^{2}$ ), an obese group (BMI $30-35 \mathrm{~kg} / \mathrm{m}^{2}$ ), and a morbidly obese group (BMI > $35 \mathrm{~kg} / \mathrm{m}^{2}$ ). All laparoscopic sleeve gastrectomy patients belonged to the morbidly obese group, while the hernia and cholecystectomy patients belonged to the remaining groups. There was no significant difference in age or sex among the groups. Further, the groups were comparable in blood pressure and blood lipid profile,

Table I. Sequences of primers used in this study

\begin{tabular}{|c|c|}
\hline Primer set & Sequence \\
\hline \multicolumn{2}{|l|}{ UCP1: } \\
\hline Forward & TAAAAACAGAGGGCGGATG \\
\hline Reverse & GCCCAATGAATACTGCCACT \\
\hline \multicolumn{2}{|l|}{ CIDEA: } \\
\hline Forward & AGGTCGGGAATAGCGAGAGT \\
\hline Reverse & AGAAACTGTCCCGTCACCTG \\
\hline \multicolumn{2}{|l|}{ CITED 1: } \\
\hline Forward & TCACTTCCGCCAATTTATC \\
\hline Reverse & TGGTTCCATTTGAGGCTACC \\
\hline \multicolumn{2}{|l|}{$T B \times 1:$} \\
\hline Forward & CAAGCTCAAGCTGACCAACA \\
\hline Reverse & CGATGGTTCTGGTAGGCAGT \\
\hline \multicolumn{2}{|l|}{ ZIC 1: } \\
\hline Forward & GCATCCCAGTTCGCTGCGCAAA \\
\hline Reverse & GGAGACACGATGGTGGGAGGCG \\
\hline \multicolumn{2}{|l|}{$\beta$-actin: } \\
\hline Forward & GCTCGCGTCGACAACGGCTC \\
\hline Reverse & CAAACATGATCTGGGTCATCTTCTC \\
\hline
\end{tabular}


Table II. Characteristics of the study participants

\begin{tabular}{|lccccc|}
\hline Parameter & $\begin{array}{c}\text { Normal weight } \\
(n=10)\end{array}$ & $\begin{array}{c}\text { Overweight } \\
(n=15)\end{array}$ & $\begin{array}{c}\text { Obese } \\
(n=10)\end{array}$ & $\begin{array}{c}\text { Morbidly obese } \\
(n=23)\end{array}$ & $P$-value \\
\hline Age [years] & $29.9 \pm 8$ & $30.5 \pm 6.7$ & $34.3 \pm 7.5$ & $34.2 \pm 5.5$ & 0.23 \\
\hline Male (\%) & 20 & 26 & 20 & 27 & 0.89 \\
\hline BMI [kg/m²] & $24.5 \pm 0.9$ & $27.1 \pm 1.2$ & $33.9 \pm 1.9$ & $42.2 \pm 5.5$ & $<0.00001^{*}$ \\
\hline Cholesterol [mmol/l] & $3.9 \pm 0.5$ & $2.4 \pm 0.4$ & $4.5 \pm 0.9$ & $4.0 \pm 0.6$ & $0.02^{*}$ \\
\hline HDL [mmol/l] & $0.9 \pm 0.3$ & $0.7 \pm 0.1$ & $1.0 \pm 0.1$ & $1.0 \pm 0.2$ & 1.2 \\
\hline Triglycerides [mmol/l] & $1.7 \pm 0.5$ & $1.7 \pm 0.3$ & $1.1 \pm 0.4$ & $1.0 \pm 0.3$ & 0.1 \\
\hline LDL [mmol/l] & $3.0 \pm 0.6$ & $3.1 \pm 0.8$ & $3.1 \pm 0.9$ & $3.1 \pm 0.8$ & 0.15 \\
\hline Systolic BP [mm Hg] & $118 \pm 14$ & $120 \pm 15$ & $115 \pm 12$ & $115 \pm 12$ & 0.11 \\
\hline Diastolic BP [mm Hg] & $71 \pm 12$ & $70 \pm 9$ & $71 \pm 13$ & $69 \pm 10$ & 0.8 \\
\hline
\end{tabular}

Data are presented as mean \pm standard deviation. There was a significant difference only in the BMI and blood cholesterol level between the groups ( $p<0.00001$ and $p=0.02$, respectively), as ascertained using the ANOVA test. *Statistically significant at $p<0.05$.

except for cholesterol, which was lower in patients belonging to the overweight group $(p=0.02)$.

\section{Expression of BAT/bAT genes in abdominal subcutaneous WAT}

The expression levels of the selected BAT/bAT genes are presented in Figure 1. Although there was higher expression of BAT/bAT genes in the groups with a lower $\mathrm{BMI}\left(<30 \mathrm{~kg} / \mathrm{m}^{2}\right)$ compared with the groups with a higher BMI $\left(>30 \mathrm{~kg} / \mathrm{m}^{2}\right)$, the difference was not significant. The mean expression of all the BAT/bAT genes was higher in the normal weight group and overweight groups compared with the obese and morbidly obese group. A statistically significant difference was found only in the expression of CIDEA and CITED1 between the normal weight and the obese group ( $p=0.01$ and $p=0.02$, respectively), while there was no statistically significant difference in the expression of UCP1, TBX1, and ZIC1 among the groups. We found that the CITED1 and CIDEA genes had higher expression (fold change) compared with other BAT/bAT genes, but this was also statistically insignificant $(p>0.05)$. Also, the correlations between the expression levels of BAT/bAT genes were high $(r=0.6-0.8, p<0.001)$, although the data are not shown here. Interestingly, female patients demonstrated higher expression of UCP1 $(p=0.03)$ and CITED1 $(p=0.06)$ compared with male patients. In addition, there was no significant effect of age on BAT/bAT gene expression ( $p=$ 0.11 ; data not shown). The medical diagnosis also had no effect on gene expression $(p>0.05)$.

\section{Correlation of BAT genes' expression with $\mathrm{BMI}$}

Figure 2 presents the relationship between BAT/bAT genes' expression (fold change) and BMI (excluding patients with morbid obesity; BMI $>35 \mathrm{~kg} / \mathrm{m}^{2}$ ). We found a significant negative correlation between the expression of BAT genes and BMI. This correlation was not found in morbidly obese patients $\left(\mathrm{BMI}>35 \mathrm{~kg} / \mathrm{m}^{2}\right)$. The strongest negative correlation was observed in the expression of CIDEA $(r=-0.5, p=0.004)$, followed by TBX1 $(r=-0.4, p=0.01)$, CITED 1 and ZIC $1(r=-0.4$, $p=0.03)$. However, the correlation of UCP1 with $\mathrm{BMI}$ remained insignificant $(r=-0.29, p=0.08)$. This is particularly noteworthy when including patients with $\mathrm{BMI}>35 \mathrm{~kg} / \mathrm{m}^{2}$, since the correlation decreased and became insignificant $(p=0.08)$ and, in addition, there was no association with $\mathrm{BMI}$ in patients with $\mathrm{BMI}>35 \mathrm{~kg} / \mathrm{m}^{2}$, as shown in Figure 3 .

\section{Correlation between BAT/bAT genes' expression and blood lipid profiles}

Table III presents a summary of the correlation of BAT/bAT genes' expression with patients' blood lipid profiles. No significant correlation was found between the expression of BAT/bAT genes and blood lipid profile $(p>0.05)$.

\section{Serum FGF21 correlation with BAT/bAT genes' expression}

Table IV summarizes the correlations of serum FGF21 with BAT/bAT genes' expression. We found that serum FGF21 was positively and significantly associated with the expression of UCP1 $(r=0.56$, $p=0.02)$ and TBX1 $(r=0.62, p=0.01)$ in patients with $\mathrm{BMI}<35 \mathrm{~kg} / \mathrm{m}^{2}$. Also, serum FGF21 was positively associated with the expression of CITED 1 and ZIC1, but it was not statistically significant ( $r=0.5, p=0.1$ and $r=0.4, p=0.09$, respectively). In contrast, among patients with morbid obesity $\left(\mathrm{BMI}>35 \mathrm{~kg} / \mathrm{m}^{2}\right)$, there was no significant correlation of FGF21 with BAT/bAT genes' expression. 
A

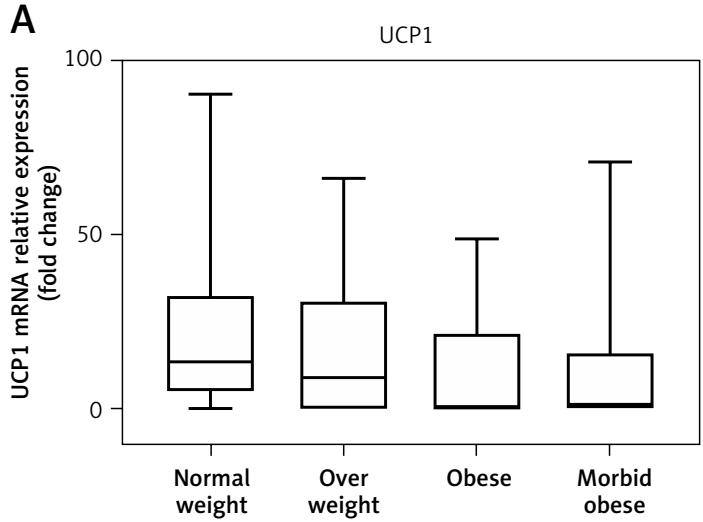

C

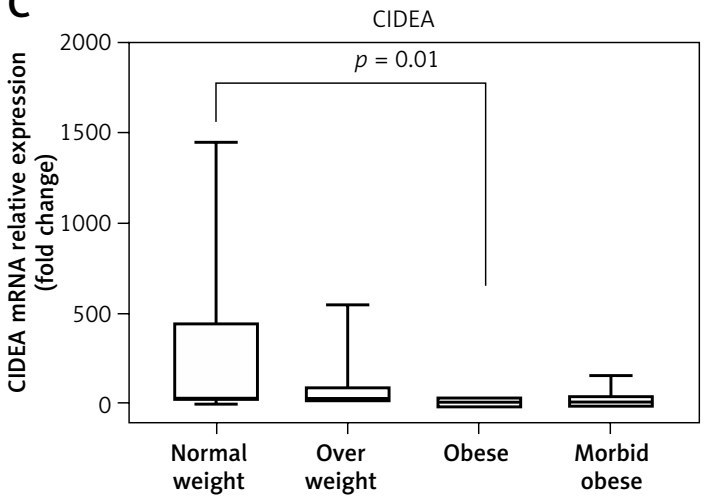

E

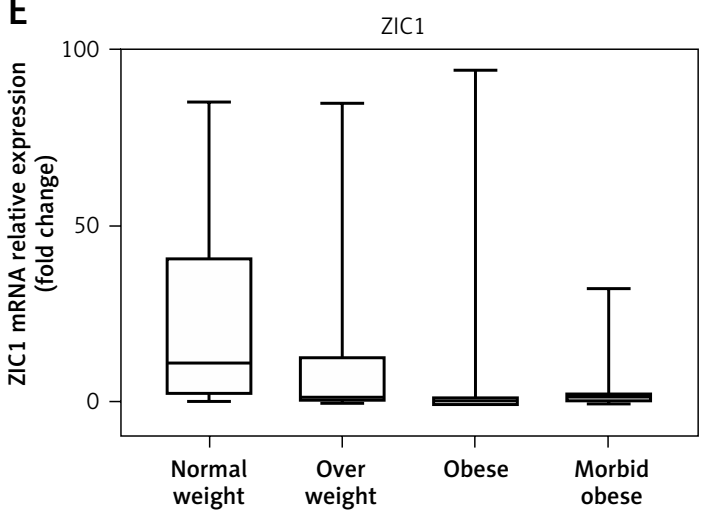

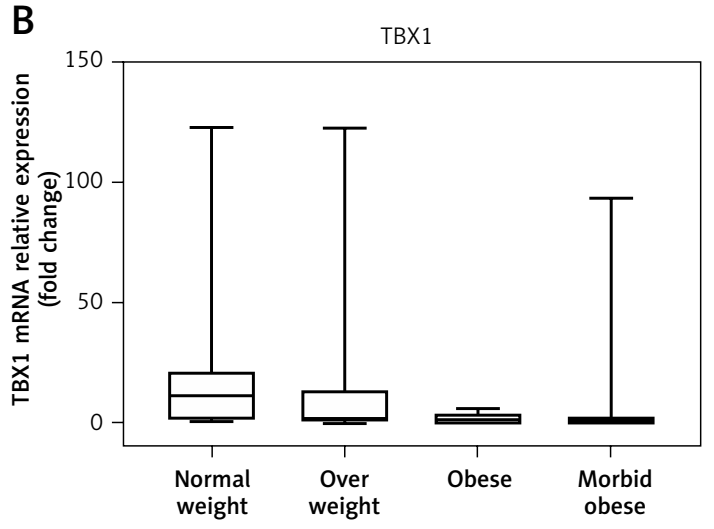

D

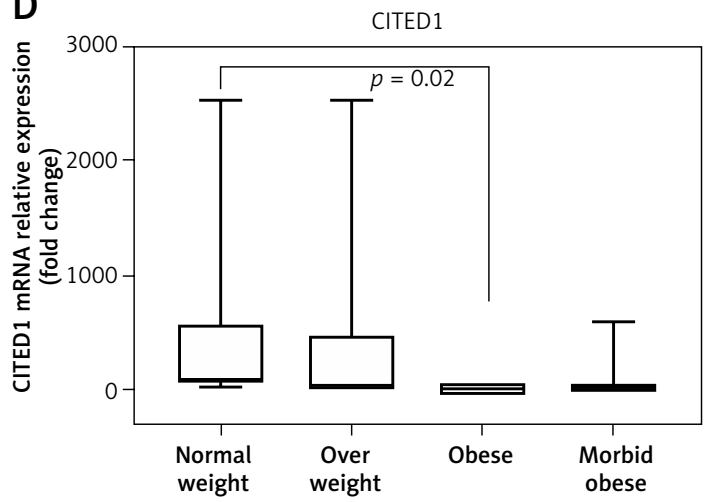

$\mathrm{F}$

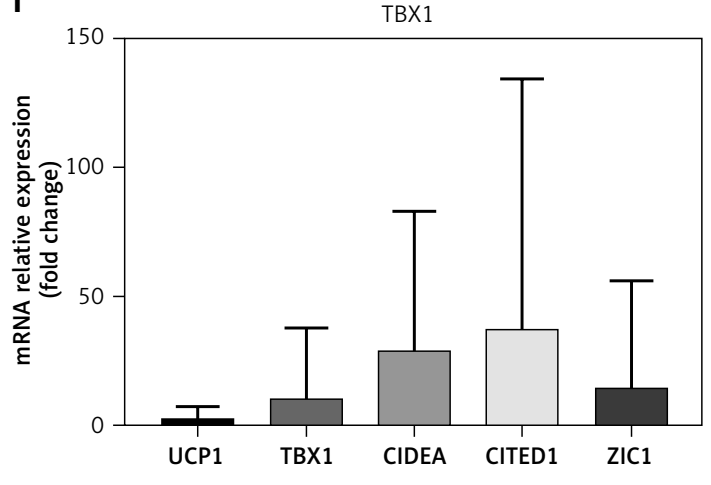

Figure 1. Relative expression of BAT/bAT genes (fold change) in abdominal subcutaneous WAT of surgical patients. A, B, C, D and E represent the median relative expression of UCP1, TBX1, CIDEA, CITED1 and ZIC1, respectively. Significant differences were found in CIDEA expression, which was significantly higher in the normal weight group than the obese group ( $p=0.01)$, and in CITED1 expression, which was higher in the normal weight group than the obese group $(p=0.02)$. Other genes (UCP1, TBX1 and ZIC1) did not show a significant difference among the groups. $\mathbf{F}$ represents the median fold change relative expression of different BAT genes. The highest expression level was observed for the CITED1 gene followed by the CIDEA gene, and the least expressed gene was UCP1, but this was statistically not significant. *Statistically significant at $p<0.05$.

Further, serum FGF21 was not associated with age, gender or BMI in our study $(p>0.05)$; however, those data are not shown here. Similarly, there was no significant difference in BMI among patients with low FGF21 (below median, $<0.25 \mathrm{ng} / \mathrm{ml}$ ) or high FGF21 (above median, $>0.25 \mathrm{ng} / \mathrm{ml} ; p=0.6$ ).

Figure 4 shows the correlation of serum FGF21 with serum cholesterol level. Serum FGF21 was positively associated with serum cholesterol level
( $r=0.4, p=0.01)$ among all patients (BMI $>35 \mathrm{~kg} /$ $\mathrm{m}^{2}$ and $<35 \mathrm{~kg} / \mathrm{m}^{2}$ ), but it was not associated with values of other blood lipids $(p>0.05)$, although the data are not shown here. In concordance, we found that patients with higher FGF21 (above median, >0.25 ng/ml) had a significantly higher blood cholesterol level than that of patients with lower FGF21 (below median, $<0.25 \mathrm{ng} / \mathrm{ml}$ ) ( $p=$ 0.002); see Figure $4 \mathrm{~B}$. 
A

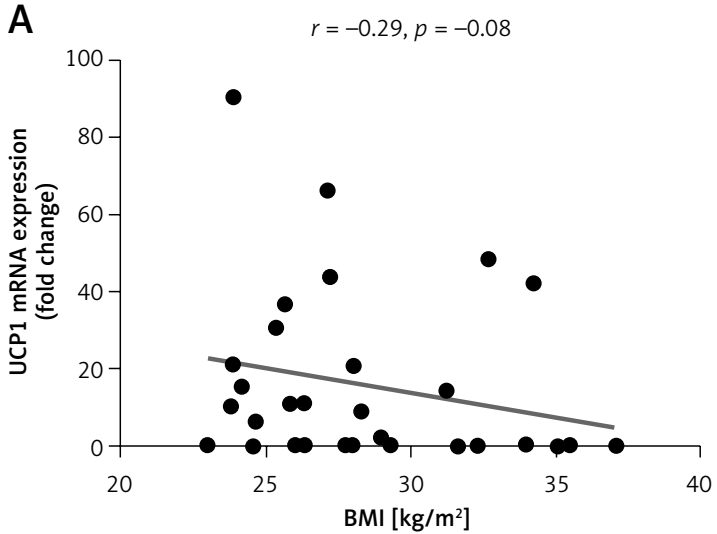

C

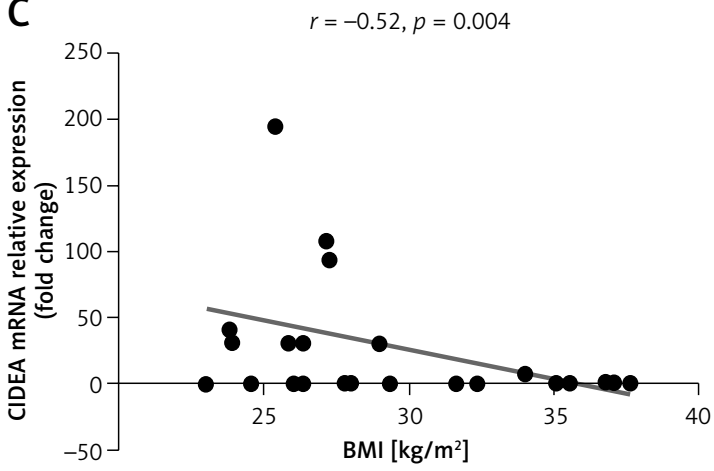

E

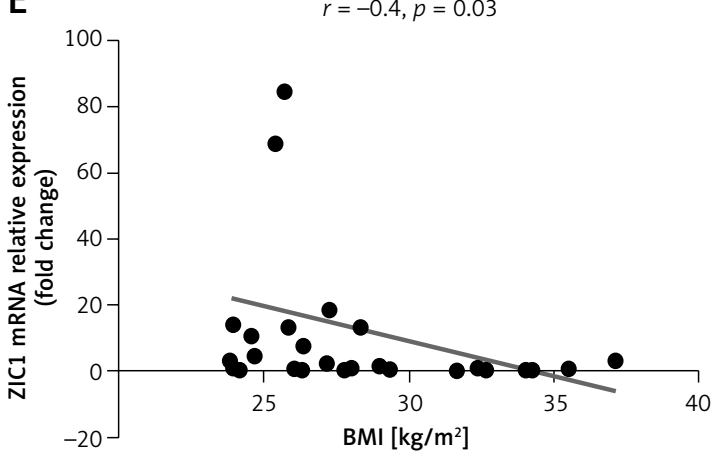

\section{Discussion}

In the current study, we found that the expression of BAT/bAT genes is low and dysregulated in obese compared with non-obese individuals. Also, we found that expression of BAT/bAT genes (TBX1, CIDEA, CITED1 and ZIC1) in the subcutaneous tissues was inversely and significantly correlated with patient BMI. This association was not observed in morbidly obese patients (BMI $>35 \mathrm{~kg} / \mathrm{m}^{2}$ ). However, this indicates an impairment in the browning process of subcutaneous tissues in obese individuals. It also indicates the importance of browning the subcutaneous tissues in maintaining body weight and preventing obesity in humans.

Moreover, the highest correlation with BMI was found in CIDEA expression ( $r=-0.5, p=0.004)$. This finding is consistent with earlier studies
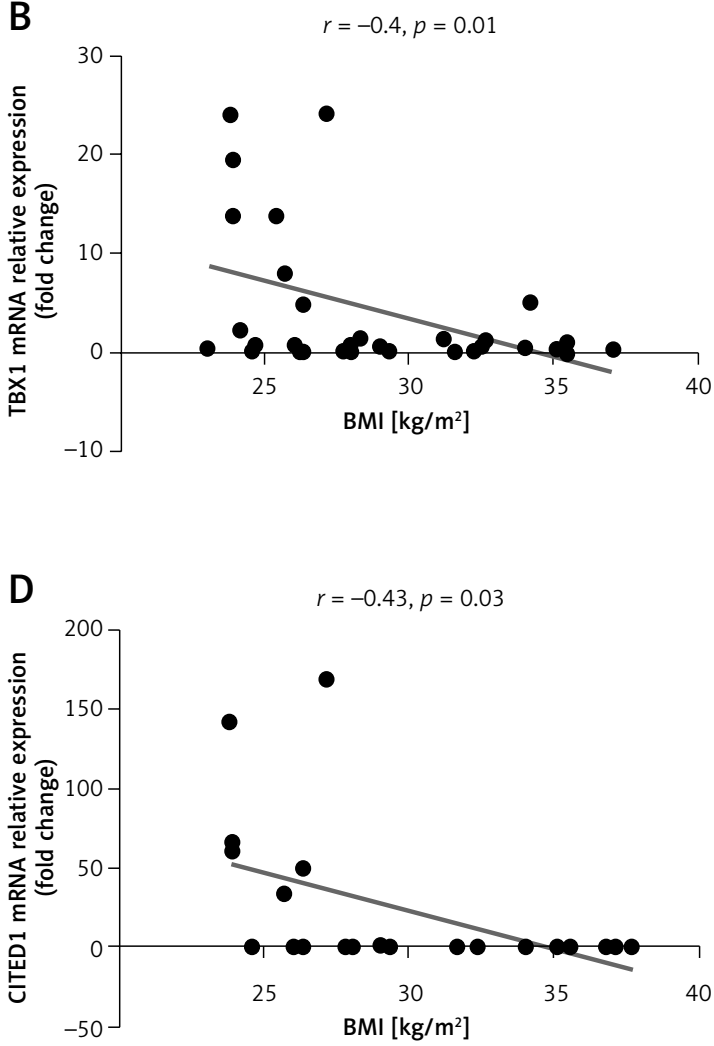

Figure 2. Relationship between BAT genes' expression (fold change) and BMI, excluding patients with morbid obesity $\left(\mathrm{BMI}>35 \mathrm{~kg} / \mathrm{m}^{2}\right)$. A, B, C, D, and E represent the correlation of relative expression of UCP1, TBX1, CIDEA, CITED 1 and ZIC1 with BMI, respectively, excluding patients with $\mathrm{BMI}>35 \mathrm{~kg} / \mathrm{m}^{2}$. A significant negative correlation was found between the expression of BAT/bAT genes and BMI, except for UCP1, which showed an insignificant correlation with $\mathrm{BMI}(p=0.08)$. Note that this correlation was not found in the patients with morbid obesity (BMI $\left.>35 \mathrm{~kg} / \mathrm{m}^{2}\right)$. The strongest correlation with $\mathrm{BMI}$ was observed in CIDEA expression $(p=$ 0.004). *Statistically significant at $p<0.05$

among ischemic limb patients and patients with metabolic syndrome [14]. Here, we provide further evidence that the CIDEA expression inversely and strongly correlates with BMI among surgical patients undergoing hernia repair or cholecystectomy. In addition, we found that this correlation becomes insignificant in severely obese patients, indicating dysregulation of CIDEA expression during severe obesity. CIDEA is a common gene expressed in both BAT and bAT. Recently, it has been demonstrated that the expression of CIDEA in WAT is a direct indicator of the browning process [15]. Our finding of lower BMI with higher expression of CIDEA could be explained by an increase in the associated browning process in subcutaneous WAT, leading to a higher metabolic rate and energy expenditure. Although CIDEA is a known negative regulator of the thermogen- 
A

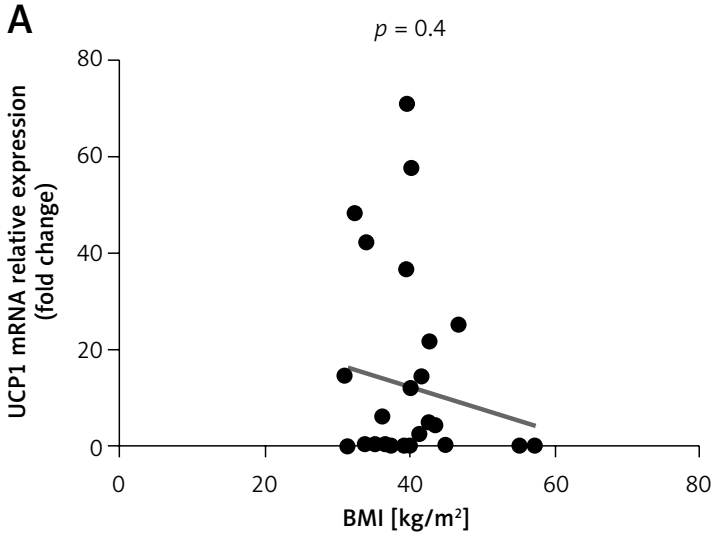

C

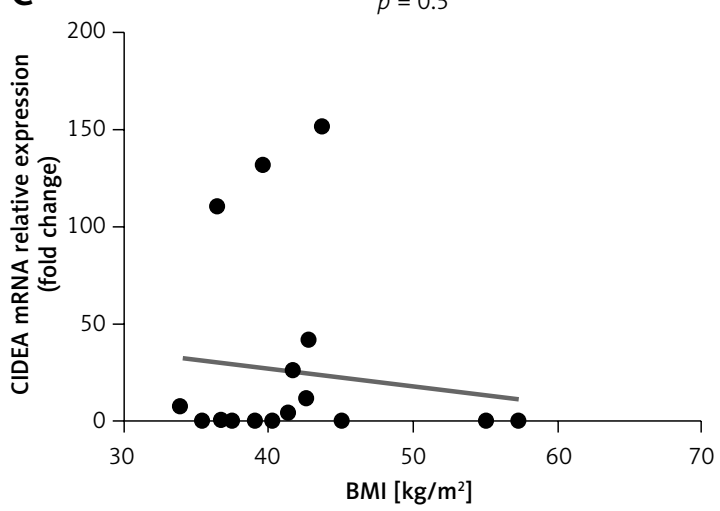

$E$

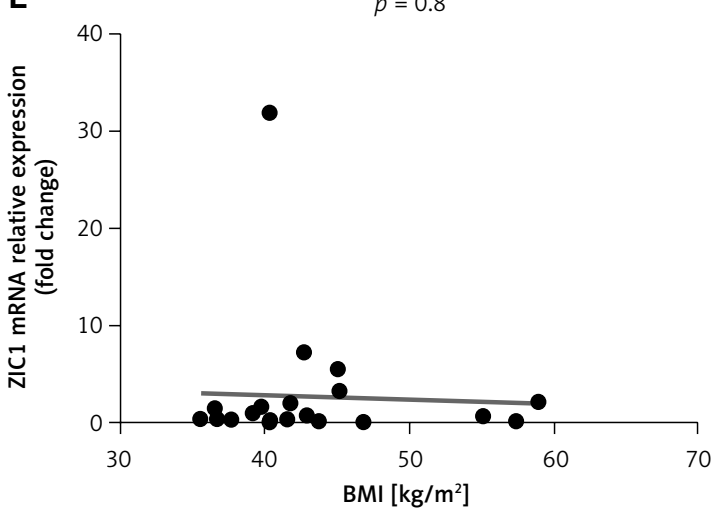

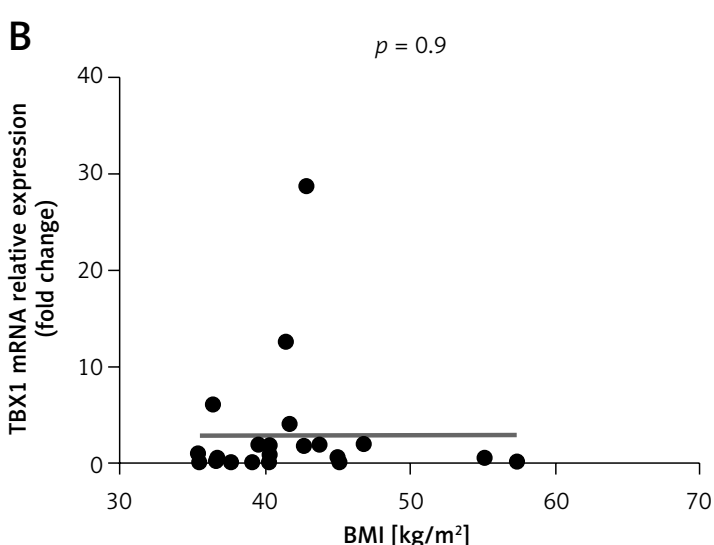

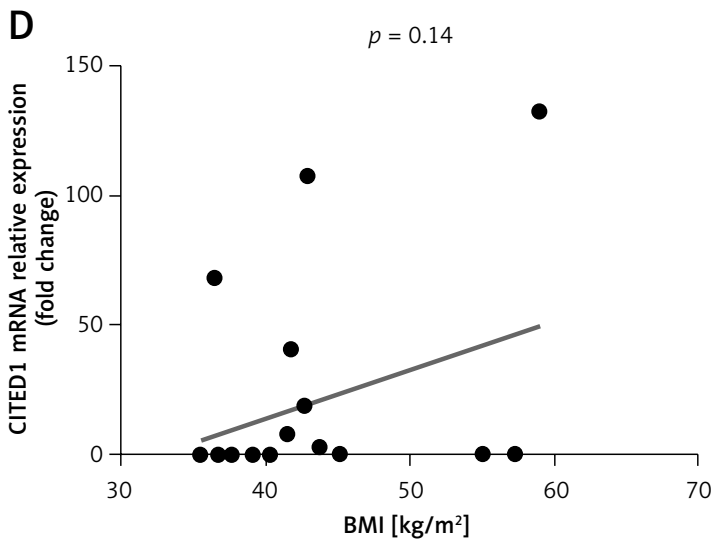

Figure 3. Relationship between BAT/bAT genes' expression (fold change) and $\mathrm{BMI}$ in patients with morbid obesity $\left(\mathrm{BMI}>35 \mathrm{~kg} / \mathrm{m}^{2}\right)$. A, B, C, D, and $\mathrm{E}$ represent the correlation of relative expression of UCP1, TBX1, CIDEA, CITED1, and ZIC1 with BMI, respectively, in patients with morbid obesity (BMI $>35 \mathrm{~kg} / \mathrm{m}^{2}$ ). No significant correlation was found between the expression of BAT genes and BMI. *Statistically significant at $p<0.05$

Table III. Correlation between BAT/bAT genes' expression and blood lipid profile

\begin{tabular}{|c|c|c|c|c|c|c|}
\hline Values & & $U C P 1$ & $T B X 1$ & CIDEA & CITED 1 & ZIC 1 \\
\hline \multirow[t]{2}{*}{ Cholesterol } & $r$ & 0.2 & 0.09 & -0.14 & 0.1 & 0.19 \\
\hline & $p$ & 0.2 & 0.1 & 0.5 & 0.6 & 0.32 \\
\hline \multirow[t]{2}{*}{$\mathrm{HDL}$} & $r$ & -0.07 & -0.12 & 0.05 & 0.1 & -0.01 \\
\hline & $p$ & 0.7 & 0.5 & 0.7 & 0.1 & 0.9 \\
\hline \multirow[t]{2}{*}{ LDL } & $r$ & -0.08 & -0.07 & 0.09 & 0.08 & 0.03 \\
\hline & $p$ & 0.6 & 0.8 & 0.9 & 0.6 & 0.8 \\
\hline \multirow[t]{2}{*}{ Triglycerides } & $r$ & -0.05 & -0.06 & -0.1 & -0.37 & 0.02 \\
\hline & $p$ & 0.7 & 0.7 & 0.6 & 0.08 & 0.9 \\
\hline
\end{tabular}

*Statistically significant at $p<0.05$. 
Table IV. Correlation summary of FGF21 with BAT/bAT genes' expressions

\begin{tabular}{|lcccccc|}
\hline Values & & UCP1 & TBX1 & CIDEA & CITED1 & ZIC1 \\
\hline BMI $<35 \mathrm{~kg} / \mathrm{m}^{2}$ & $r$ & 0.56 & 0.62 & 0.09 & 0.5 & 0.4 \\
\cline { 2 - 6 } & $p$ & $0.02^{*}$ & $0.01^{*}$ & 0.7 & 0.1 & 0.09 \\
\hline BMI $>35 \mathrm{~kg} / \mathrm{m}^{2}$ & $r$ & 0.09 & 0.13 & 0.17 & 0.07 & 0.3 \\
\cline { 2 - 7 } & $p$ & 0.7 & 0.5 & 0.5 & 0.7 & 0.8 \\
\hline
\end{tabular}

${ }^{*}$ Statistically significant at $p<0.05$.

esis process [15], higher expression of CIDEA in patients with lower BMI could be a negative feedback mechanism to counteract a high metabolic rate in those individuals through suppressing the thermogenesis process.

Further, $T B X 1$ is a transcription factor highly expressed in bAT [16]. It plays an important role in differentiation processes of many tissue types [17]. Nevertheless, there are not enough data available about the role of TBX1 in adipose tissues. We found that $T B X 1$ correlated negatively with $\mathrm{BMI}$ in patients without severe obesity. No earlier study had reported this correlation in humans. Similarly, CITED1, a non-DNA binding transcriptional co-regulator [18], was recently found to be a molecular marker that distinguishes bAT from other fat tissues [16]. CITED1 was found to correlate negatively with $\mathrm{BMI}$ in patients without severe obesity. This association has not been reported before.

Also, the expression of BAT specific gene (ZIC1) was negatively associated with BMI in patients without severe obesity. Previously, an in vitro study showed that the expression of ZIC 1 is not changed between adipocytes derived from obese or lean individuals [19]. In contrast, our direct assessment of ZIC1 expression in WAT samples suggests that $Z I C 1$ expression correlates with BMI inversely and has a role in browning of WAT in humans. Remarkably, the expression of UCP1 was correlated with BMI at insignificant levels $(r=-0.29, p=0.08)$. This

\section{A}

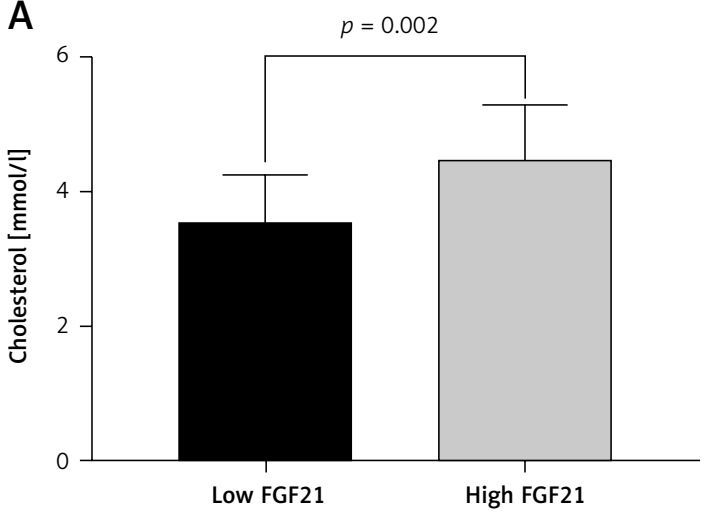

was consistent with the findings of an earlier study among children [20]. However, it was found that UCP1 mRNA level is not an indicator of the thermogenesis process in bAT, and thermogenesis in bAT can occur independently of UCP1 [21]. To determine the role of mRNA of UCP1 (as well as other BAT/bAT genes) in the thermogenesis process, a functional assessment of cell respiration and bioenergetics is required. In addition, we found that the expression bAT-specific genes (TBX1 and CITED1) was highly correlated with the expression of BAT-specific gene $(Z I C 1 ; p<0.0001)$. This suggests that the browning process requires the recruitment of BAT cells or BAT gene pathways as well. We also found that females have higher UCP 1 expression compared with males $(p=0.03)$; this was consistent with an earlier study [22]. There was no effect of age on bAT/BAT genes' expression.

Interestingly, BAT activation has been found to be a powerful tool in reducing blood lipids in mice $[23,24]$. In contrast, our study demonstrates an insignificant correlation between the expression of BAT/bAT genes and blood lipid profiles. This finding is similar to an earlier study that reported no correlation found between CIDEA gene expression and blood lipid profile [14]. In our study, only the expression of CITED 1 was negatively associated with the serum triglyceride level at an insignificant level $(r=-0.37, p=0.08)$.

Animal and in vitro studies have suggested that FGF21 is a powerful inducer of bAT in WAT,

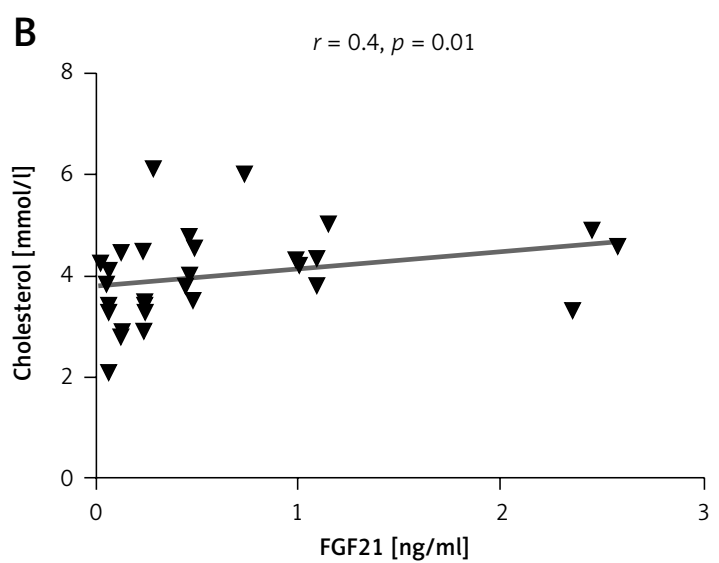

Figure 4. Correlation of serum FGF21 with blood cholesterol level. A - shows that serum FGF21 is positively associated with blood cholesterol level, regardless of a patient's BMI $(p=0.01)$. B - shows that patients with a lower FGF21 level $(<0.25 \mathrm{ng} / \mathrm{ml})$ had significantly lower blood cholesterol $(p=0.002)$. Statistically significant at $p<0.05$ 
considered a promising anti-obesity agent due to its beneficial effects on body weight and metabolism [25]. In the current study, we found that the serum FGF21 level was positively associated with subcutaneous expression of UCP1 and TBX1, a correlation not found in severely obese patients. This finding was consistent with an earlier study among HIV patients that showed a correlation between FGF21 and UCP1 expression in subcutaneous tissues in the dorsocervical region [26]. Herein, however, we provide further evidence about the importance of FGF21 in inducing in human subcutaneous WAT.

The metabolic signaling of FGF21 is found to be impaired in obesity. However, it has been demonstrated that administering FGF21 to obese mice resulted in attenuated expression of FGF21 target genes compared with non-obese mice [27]. This led to the inference that obesity is an FGF21 resistive disorder. In addition, another study reported impairment in FGF21 lipogenic and anti-adipogenic actions in adipocytes isolated from obese type 2 diabetes patients [28]. In concordance with that, our study demonstrated that serum FGF21 was not associated with the expression of UCP1 and TBX1 in individuals with severe obesity (BMI $>35 \mathrm{~kg} / \mathrm{m}^{2}$ ), suggesting impairment of the FGF21 signaling pathway. Another mechanism that could affect the FGF21 function during obesity is epigenetic methylation; however, it has recently been demonstrated that reducing FGF21 methylation in the liver enhances FGF21 expression after activation by peroxisome proliferator-activated receptors (PPAR), suggesting that reducing FGF21 methylation could be a potential mechanism for improving its function in resisting obesity [29].

In conclusion, we provide evidence that the expression of BAT/bAT (beige fat) in subcutaneous tissues is reduced in obese individuals, particularly the expression of CIDEA and CITED1. Our study is the first to demonstrate an association of TBX1, CITED 1, and ZIC1 with BMI, while it is also the first to demonstrate an association of serum FGF21 with the expression of TBX1 in subcutaneous tissues in patients with $\mathrm{BMI}<35 \mathrm{~kg} / \mathrm{m}^{2}$.

Our study has several limitations: a low sample number, only abdominal subcutaneous tissues involved, and no comparison between different fat deposits. Furthermore, this was a descriptive study, unable to explain the underlying mechanisms of bAT regulation of body weight.

In view of the current evidence, we conclude that the dysfunction in the browning process of subcutaneous tissues may contribute to obesity pathogenesis. Finding a mechanism to correct BAT/bAT dysfunction, particularly in subcutaneous WAT, could be an effective way to treat obesity. As a fundamental step, it is important to enhance our understanding of physiological and pathophysi- ological mechanisms of bAT functions in human subcutaneous tissues. In conclusion, our data suggest that the browning of subcutaneous tissues in humans is reduced and dysregulated in obese individuals. Further studies are needed to enhance our understanding of the role of subcutaneous tissues in regulating body weight and metabolism in humans.

\section{Acknowledgments}

The authors would like to thank Deanship of scientific research at King Saud University for funding and supporting this research through the initiative of DSR Graduate Students Research Support (GSRS). Also, to acknowledge the support of employee in the Stem Cells Research Center and the Research Center at the College of Medicine, King Saud University.

\section{Conflict of interest}

The authors declare no conflict of interest.

\section{References}

1. Ricquier D. Respiration uncoupling and metabolism in the control of energy expenditure. Proc Nutr Soc 2005; 64: 47-52.

2. Cypess AM, White AP, Vernochet $C$, et al. Anatomical localization, gene expression profiling and functional characterization of adult human neck brown fat. Nat Med 2013; 19: 635-9.

3. Wu J, Bostrom P, Sparks LM, et al. Beige adipocytes are a distinct type of thermogenic fat cell in mouse and human. Cell 2012; 150: 366-76.

4. Harms M, Seale P. Brown and beige fat: development, function and therapeutic potential. Nat Med 2013; 19: 1252-63.

5. Wang L, Teng R, Di L, et al. PPAR alpha and Sirt1 mediate erythropoietin action in increasing metabolic activity and browning of white adipocytes to potect against obesity and metabolic disorders. Diabetes 2013; 62: 4122-31.

6. Carey AL, Formosa MF, Van Every B, et al. Ephedrine activates brown adipose tissue in lean but not obese humans. Diabetologia 2013; 56: 147-55.

7. van Marken Lichtenbelt WD, Vanhommerig JW, Smulders NM, et al. Cold-activated brown adipose tissue in healthy men. N Engl J Med 2009; 360: 1500-8.

8. Gavrieli A, Mantzoros CS. Novel molecules regulating energy homeostasis: physiology and regulation by macronutrient intake and weight loss. Endocrinol Metabol 2016; 31: 361-72.

9. Lin Z, Tian H, Lam KSL, et al. Adiponectin mediates the metabolic effects of FGF21 on glucose homeostasis and insulin sensitivity in mice. Cell Metabol 2013; 17: 779-89.

10. Hondares E, Rosell M, Gonzalez FJ, Giralt M, Iglesias R, Villarroya F. Hepatic FGF21 expression is induced at birth via PPAR in response to milk intake and contributes to thermogenic activation of neonatal brown fat. Cell Metabol 2010; 11: 206-12.

11. Fisher FF, Kleiner S, Douris N, et al. FGF21 regulates PGC-1 and browning of white adipose tissues in adaptive thermogenesis. Genes Developm 2012; 26: 271-81. 
12. Hondares $\mathrm{E}$, Iglesias $\mathrm{R}$, Giralt $\mathrm{A}$, et al. Thermogenic activation induces FGF21 expression and release in brown adipose tissue. J Biol Chem 2011; 286: 12983-90.

13. Keys A, Fidanza F, Karvonen MJ, Kimura N, Taylor HL. Indices of relative weight and obesity. J Chron Dis 1972; 25: 329-43.

14. Gummesson A, Jernås M, Svensson PA, et al. Relations of adipose tissue CIDEA gene expression to basal metabolic rate, energy restriction, and obesity: populationbased and dietary intervention studies. J Clin Endocrinol Metabol 2007; 92: 4759-65.

15. Fischer AW, Shabalina IG, Mattsson CL, et al. UCP1 inhibition in Cidea-overexpressing mice is physiologically counteracted by brown adipose tissue hyperrecruitment. Am J Physiol Endocrinol Metabol 2017; 312: E72-87.

16. Sharp LZ, Shinoda K, Ohno H, et al. Human BAT possesses molecular signatures that resemble beige/brite cells. PLoS One 2012; 7: e49452.

17. Wilson V, Conlon FL. The T-box family. Genome Biol 2002; 3: reviews3008.

18. Howlin J, Cirenajwis H, Lettiero B, et al. Loss of CITED1, an MITF regulator, drives a phenotype switch in vitro and can predict clinical outcome in primary melanoma tumours. Peer J 2015; 3: e788.

19. Carey AL, Vorlander C, Reddy-Luthmoodoo M, et al. Reduced UCP-1 content in in vitro differentiated beige/ brite adipocytes derived from preadipocytes of human subcutaneous white adipose tissues in obesity. PLoS One 2014; 9: e91997.

20. Rockstroh D, Landgraf K, Wagner IV, et al. Direct evidence of brown adipocytes in different fat depots in children. PLoS One 2015; 10: e0117841.

21. Keipert S, Jastroch M. Brite/beige fat and UCP1 - is it thermogenesis? Biochim Biophys Acta 2014; 1837: 1075-82.

22. Nookaew I, Svensson PA, Jacobson P, et al. Adipose tissue resting energy expenditure and expression of genes involved in mitochondrial function are higher in women than in men. J Clin Endocrinol Metabol 2013; 98: E370-8.

23. Berbeé JFP, Boon MR, Khedoe PP, et al. Brown fat activation reduces hypercholesterolaemia and protects from atherosclerosis development. Nat Commun 2015; 6: 6356.

24. Hoeke G, Kooijman S, Boon MR, Rensen PCN, Berbeé JFP. Role of brown fat in lipoprotein metabolism and atherosclerosis. Circ Res 2016; 118: 173-82.

25. Fenzl A, Kiefer FW. Brown adipose tissue and thermogenesis. Horm Mol Biol Clin Investig 2014; 19: 25-37.

26. Srinivasa S, Wong K, Fitch KV, et al. Effects of lifestyle modification and metformin on irisin and FGF21 among HIV-infected subjects with the metabolic syndrome. Clin Endocrinol 2015; 82: 678-85.

27. Woo YC, Xu A, Wang Y, Lam KSL. Fibroblast growth factor 21 as an emerging metabolic regulator: clinical perspectives. Clin Endocrinol 2013; 78: 489-96.

28. Gallego-Escuredo JM, Gómez-Ambrosi J, Catalan V, et al. Opposite alterations in FGF21 and FGF19 levels and disturbed expression of the receptor machinery for endocrine FGFs in obese patients. Int J Obes 2015; 39: 121-9.

29. Yuan X, Tsujimoto K, Hashimoto K, et al. Epigenetic modulation of Fgf21 in the perinatal mouse liver ameliorates diet-induced obesity in adulthood. Nat Commun 2018; 9: 636. 